\title{
Management of Spontaneous Rupture of Liver Tumours
}

\author{
P. Marinia V. Vilgrain ${ }^{b}$ J.Belghitia \\ Departments of a Hepatopancreatobiliary Surgery and ${ }^{b}$ Radiology, Beaujon Hospital, Assistance Publique, \\ University Paris 7, Clichy, France
}

\section{Key Words}

Hepatocellular carcinoma . Adenoma .

Haemoperitoneum, rupture

\begin{abstract}
Spontaneous ruptures of a liver tumour are often considered as a potentially life-threatening situation. The aim of the present study was to evaluate both clinical features and treatment in a subgroup of patients with ruptured liver tumours. From 1995 to 2000, 20 patients were referred to our centre for spontaneous rupture of a liver tumour associated with haemoperitoneum. Hepatocellular carcinoma (HCC) was present in 13 patients (11 men and 2 women) aged from 48 to 72 years (mean 62) and adenoma in 7 women aged from 23 to 52 years (mean 35). Although all patients experienced sudden abdominal pain and anaemia, shock at admission was present in $4(20 \%)$ patients including 3 with HCC. In patients with HCC, severe liver insufficiency (Child-Pugh C) was present in 5 cases including the 3 shocked patients. No treatment was undertaken in 2 patients, transarterial embolization was performed in 9 cases and 5 patients underwent delayed resection. In hospital, mortality was observed in $3(23 \%)$ patients, all of them had severe liver insufficiency. Long-term survival was observed in patients with good liver function who underwent resection.
\end{abstract}

In patients with adenoma, shock at admission was observed in only 1 patient under anticoagulation treatment. Emergency resection was performed in 3 cases. A decrease of the tumour size was observed in patients who underwent delayed resection resulting in a lower rate of peri-operative transfusion. In conclusion, this study confirms that the majority of patients with ruptured liver tumours had no evidence of haemodynamic instability and therefore should be initially managed conservatively. In patients with single ruptured HCC associated with good liver function, long-term survival can be observed after liver resection. Delayed resection facilitated the operative procedure in patients with ruptured adenoma.

Copyright @2002 S. Karger AG, Basel

\section{Introduction}

The risk of spontaneous rupture is present in both benign and malignant liver cell tumours. Rupture of hepatocellular carcinoma (HCC) occurs in about $10-15 \%$ [1] of patients while rupture is the mode of presentation of nearly $50 \%$ of patients with adenoma [2]. Because some patients may present with progressive abdominal distension and anaemia without haemodynamic decompensation while others present with hypovolaemic shock, accurate clinical diagnosis of spontaneous rupture of liver

\begin{tabular}{ll}
\hline KARGER & (c) 2002 S. Karger AG, Basel \\
Fax +4161306 1234 & 0253-4886/02/0192-0109\$18.50/0 \\
$\begin{array}{l}\text { E-Mail karger@karger.ch } \\
\text { www.karger.com }\end{array}$ & $\begin{array}{l}\text { Accessible online at: } \\
\text { www.karger.com/journals/dsu }\end{array}$
\end{tabular}

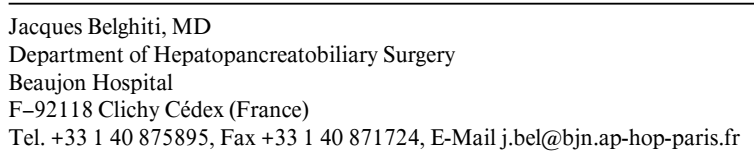


Table 1. Characteristics and outcome in 13 patients with ruptured $\mathrm{HCC}$

\begin{tabular}{llrrlllll}
\hline Age & Shock & \multicolumn{2}{c}{$\begin{array}{c}\text { Tumours Tumour } \\
\text { size }\end{array}$} & Child & $\begin{array}{l}\text { Emergency TAE } \\
\text { resection }\end{array}$ & $\begin{array}{l}\text { Delayed } \\
\text { resection }\end{array}$ \\
\hline 62 & - & 1 & 4 & A & - & - & + & Alive 32 months \\
82 & - & $>5$ & 5 & C & - & + & - & Died 4 months \\
43 & + & 3 & 10 & B & - & + & + & Died 3 months \\
72 & - & 4 & 7 & C & - & + & - & Died 5 months \\
63 & + & 1 & 10 & C & - & + & - & Died 3 days \\
51 & - & $>5$ & 12 & C & - & - & - & Died 6 days \\
58 & - & 3 & 6 & A & - & + & - & Alive 9 months \\
66 & + & 2 & 4 & C & - & + & - & Died 23 days \\
52 & - & 1 & 7 & A & - & - & + & Alive 12 months \\
75 & - & 1 & 10 & A & - & + & + & Alive 50 months \\
48 & - & 2 & 17 & A & - & + & + & Alive 12 months \\
56 & - & 1 & 6 & B & - & + & - & Died 6 months \\
74 & - & $>5$ & 7 & B & - & - & - & Died 6 months \\
\hline
\end{tabular}

tumours is not easy. The variation of clinical presentation may explain variations in the management of ruptured tumours. Various treatment options have been proposed including conservative treatment [3], transarterial embolization (TAE) [4] and emergency liver resection [5]. In this study the clinical feature and the treatment of 20 patients with ruptured tumours associated with haemoperitoneum were reviewed.

\section{Patients and Methods}

Between January 1995 and December 2000, the charts of all patients admitted in our surgical unit for spontaneous rupture of liver cell tumours were reviewed. Patients with intratumoral bleeding without haemoperitoneum and patients with haemorrhagic ascites without liver tumours were excluded from analysis. Among the 20 patients included in this study, ruptured $\mathrm{HCC}$ was responsible of the haemoperitoneum in 13 and adenoma in 7. The diagnosis of HCC was made histologically in 10 cases and on the basis of elevated $\alpha$ foetoprotein $>200 \mathrm{ng} / \mathrm{ml}$ in 3 cases. The presence of cirrhosis was established in patients who underwent liver resection. The diagnosis of adenoma was made histologically in all cases. In patients operated, a distinction was made between emergency resection within $48 \mathrm{~h}$ of admission and delayed resection.

Patients with HCC included 11 men and 2 women with a mean age of 62 years (range 48-74). In patients who underwent tumour resection, underlying cirrhosis was present in 4 and fibrosis in 1 . Chronic liver disease was attributed to hepatitis B virus in 2 and to hepatitis $C$ virus in 4 patients; 5 patients had history of heavy alcohol consumption including 1 with hepatitis $C$. In 3 cases the aetiology of underlying liver disease was unknown.

Patients with adenoma were women in all cases with a mean age of 35 years (range 23-52). All had a history of oral contraceptive use with a mean duration of 9.7 years, ranging from 3 to 20 years. In 6 patients, bleeding was the first presentation of the adenoma while 1 was known to have a liver tumour.

\section{Results}

\section{Patients with $\mathrm{HCC}$}

All patients experienced sudden abdominal pain before admission; 3 (23\%) patients were in hypovolaemic shock on admission; the remainder were haemodynamically stable. As shown in table 1 , only $4(31 \%)$ patients had a single tumour. The mean tumour diameter was $8.3 \mathrm{~cm}$, ranging from 4 to $17 \mathrm{~cm}$. According to Child-Pugh classification, liver function was impaired in 7 (54\%) cases including 5 with severe liver insufficiency (ChildPugh C). No treatment was undertaken in 2 patients with poor general condition and multiple tumours. No patients underwent emergency resection while 5 underwent delayed resection from 1 to 3 months after admission. TAE was performed in 9 (69\%) cases up to 4 days after admission. All shocked patients underwent TAE, while other patients underwent transarterial chemoembolization (TACE) including 3 before delayed resection. The hospital mortality rate was $23 \%$, including all patients with severe impaired liver function. Among the 4 patients who survived more than 12 months, all had normal liver function and underwent liver resection including 3 with a single tumour (fig. 1).

\section{Patients with Adenoma}

All patients experienced sudden abdominal pain before admission. Although the mean haemoglobin level was $8.9 \mathrm{~g} / 1$, ranging from 4 to $11 \mathrm{~g} / 1$, all patients but 1 were haemodynamically stable. The patient with hypovolaemic shock on admission with a haemoglobin level of $4.2 \mathrm{~g} / \mathrm{l}$ was treated for 2 weeks with anticoagulation for a 

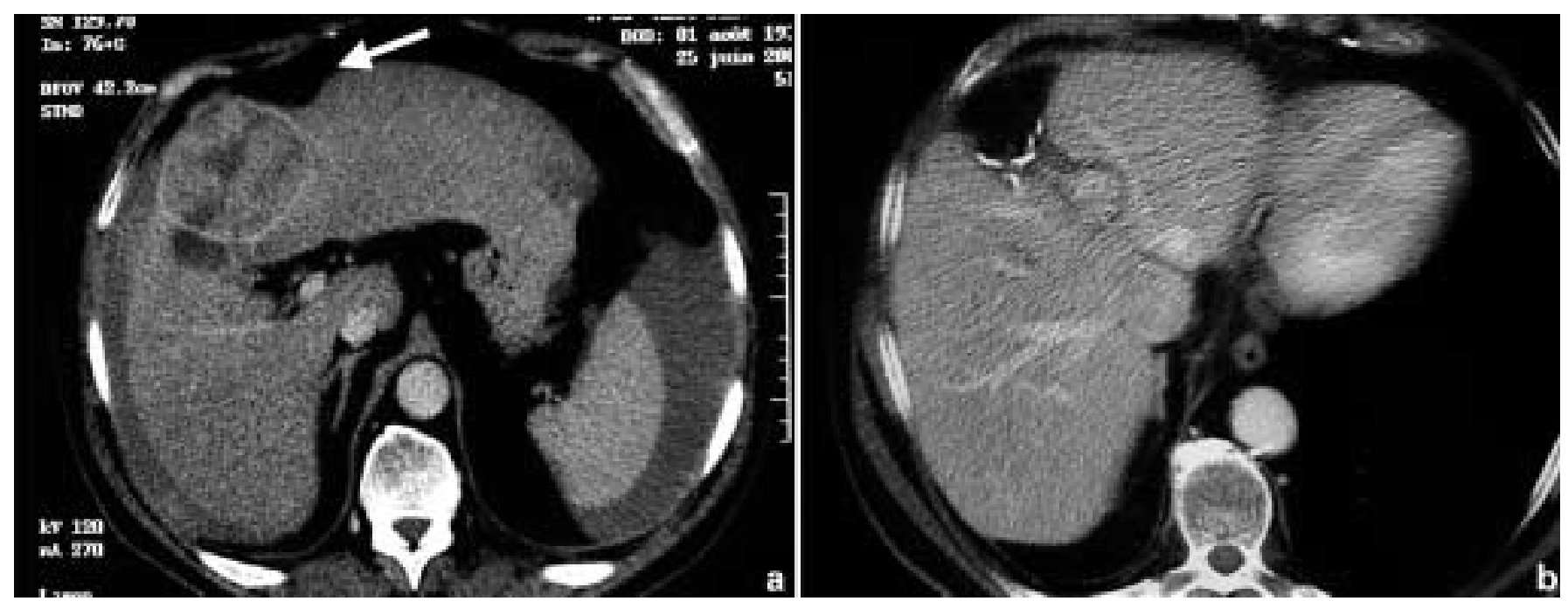

Fig. 1. Patient with ruptured HCC. a CT scan after admission showing a single tumour (arrow) associated with haemoperitoneum. b CT scan 1 year later after liver resection.

Table 2. Characteristics and outcome of 7 patients with ruptured adenoma

\begin{tabular}{rlllllllll}
\hline Year & Age & Shock & $\begin{array}{l}\text { Haemo- } \\
\text { globin } \\
\text { level, g/l }\end{array}$ & $\begin{array}{l}\text { Tumour } \\
\text { size at } \\
\text { admission }\end{array}$ & $\begin{array}{l}\text { Tumour } \\
\text { size before } \\
\text { resection }\end{array}$ & $\begin{array}{l}\text { Emergency } \\
\text { resection }\end{array}$ & $\begin{array}{l}\text { Delayed } \\
\text { resection }\end{array}$ & $\begin{array}{l}\text { Trans- } \\
\text { fusion }\end{array}$ \\
\hline 1995 & 37 & - & 11 & 30 & 30 & + & + & - & 2 \\
1996 & 23 & - & 8 & 14 & 14 & + & + & - & 6 \\
1997 & 33 & - & 9 & 6 & 5 & - & - & + & 0 \\
1999 & 52 & - & 9 & 20 & 15 & - & - & + & 4 \\
2000 & 38 & - & 11 & 14 & 10 & - & - & + & 0 \\
2001 & 42 & + & 4 & 15 & 15 & + & - & - & 16 \\
2001 & 37 & - & 10 & 12 & 6 & - & + & + & 0 \\
\hline
\end{tabular}

phlebitis. As shown in table 2, the mean tumour diameter was $16 \mathrm{~cm}$, ranging from 6 to $30 \mathrm{~cm}$. Emergency resection was performed in 3 patients including 1 with haemodynamic shock. Among the 3 patients treated during the first period (1995-1997), 2 were operated in emergency whatever clinical presentation, while the third patient, operated in emergency during the second period, experienced haemodynamic shock. All patients operated in emergency received peri-operative blood transfusion as compared to one quarter who underwent delayed liver resection. Delayed resection was performed up to 6 months after initial admission. In 1 patient a well-differentiated area of HCC was present in the adenoma. As illustrated in figure 2, the decrease of tumour volume was observed in patients who underwent delayed liver resection. The rate of transfusion in patients who underwent delayed liver resection was not influenced by the presence of pre-operative TAE.

\section{Discussion}

This study, reporting a series of 20 patients with a spontaneous rupture of a liver tumour during a 6-year period, confirms that the occurrence of this complication is not exceptional in a tertiary liver surgery unit. As reported in other studies, $\mathrm{HCC}$ with chronic liver disease and adenoma were the most frequent tumours at risk of spontaneous rupture [6]. 

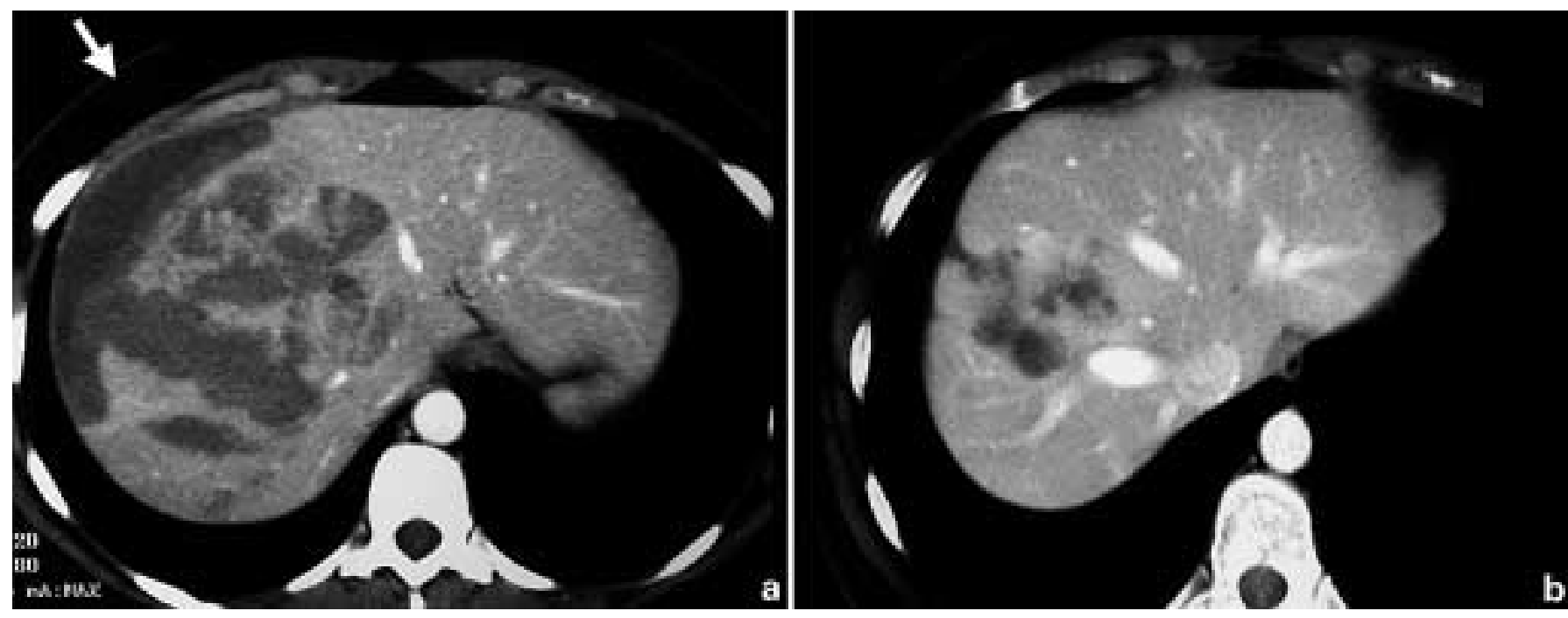

Fig. 2. Patient with ruptured adenoma. a $C T$ scan after admission showing haematoma surrounding the tumour (arrow). b CT scan 6 months later before delayed liver resection showing regression of the haematoma.

Although clinical and biological manifestation of bleeding was present in all patients with haemoperitoneum, haemodynamic instability was observed in only $20 \%$ of cases. As previously reported in patients with $\mathrm{HCC}$, bleeding from ruptured tumour is not necessarily exsanguinating nor progressive $[1,6]$. In the present series, haemodynamic shock was present in less than $25 \%$ of our patients with ruptured HCC. All of them had poor liver function and they died within the first 3 months. Results of the present study confirm that shock at presentation when associated with poor liver function had a poor life expectancy irrespective of treatment modalities $[1,6]$. None of our patients with ruptured HCC underwent emergency resection. As reported by others, these resections were mostly palliative, and were associated with an operative death rate of about one third [6]. TAE could be efficient in patients with good liver function and progressive bleeding [4]. In patients with haemodynamic stability without portal thrombosis, TACE was indicated as the definitive treatment in nonresectable patients $[1$, 7]. However, the majority of our patients treated by TACE die within the first year from tumour progression. Our study confirms that delayed resection was the only treatment associated with a long-term survival in the subgroup of patients with good liver function and resectable tumour $[1,6,8,9]$. In this subgroup of patients, TACE allows an accurate radiological evaluation before planning the resection.
Patients with ruptured adenoma are healthy young women who experienced sudden abdominal pain, haemoperitoneum and anaemia. This clinical feature is considered as a life-threatening situation justifying emergency resection for many authors [10,11]. High mortality rates after emergency resection have been published [2]. Results of the present study confirm the series of Terkivatan et al. [12] in favour of a more conservative approach. Although all of our patients with ruptured adenoma experienced abdominal pain and anaemia, haemodynamic instability was observed in only 1 patient. In this patient, rupture of adenoma occurred during a medical treatment with anticoagulants. This patient underwent difficult emergency resection requiring more than 15 units of blood. Similarly, during the first period of our study, all of our patients who underwent emergency resection required blood transfusions. The presence of haemodynamic stability led us to adopt a conservative approach with delayed resection up to 6 months after tumour rupture. Emergency-selective TAE might be considered as a therapeutic adjunct. Delayed resection was associated with a low rate of transfusion during resection. The main factor for this change was related to the dramatic decrease of the tumour size. The decrease of the tumour size was due to the absorption of the haematoma surrounding the tumour. The presence of well-differentiated HCC in 1 patient with adenoma led us to advocate liver resection even if the tumour becomes invisible after conservative 
treatment. This conservative treatment included stop of oral contraceptives and was followed by repeated CT scan [12].

In conclusion, in the majority of cases, patients with ruptured liver tumours had no evidence of haemodynamic instability and therefore should be initially man- aged conservatively. Delayed resection is advocated in patients with ruptured HCC associated with good liver function. In patients with ruptured adenoma, a delayed resection should be performed after regression of the haematoma surrounding the tumour.

\section{References}

1 Zhu LX, Wang GS, Fan ST: Spontaneous rupture of hepatocellular carcinoma. Br J Surg 1991;78:463-466.

2 Shortell CK, Schwartz SI: Hepatic adenoma and focal nodular hyperplasia. Surg Gynecol Obstet 1991;173:426-431.

3 Xu HS, Yan JB: Conservative management of spontaneous ruptured hepatocellular carcinoma. Am Surg 1994;60:629-633.

4 Ngan H, Tso WK, Lai CL, Fan ST: The role of hepatic arterial embolization in the treatment of spontaneous rupture of hepatocellular carcinoma. Clin Radiol 1998;53:338-341.
5 Chiappa A, Zbar A, Audisio RA, Paties C, Bertani E, Staudacher C: Emergency liver resection for ruptured hepatocellular carcinoma complicating cirrhosis. Hepatogastroenterology 1999;46:1145-1150.

6 Dewar GA, Griffin SM, Ku KW, Lau WY, Li AKC: Management of bleeding liver tumours in Hong Kong. Br J Surg 1991;78:463-466.

7 Boyer JC, Zins M, Vilgrain V, Sibert A, Najmark D, Vullierme MP, Erlinger S, Belghiti J, Menu Y: Hemoperitoneum caused by spontaneous rupture of hepatocellular carcinoma. Value and prognostic factors of hepatic artery embolization. J Radiol 1995;76:365-369.

8 Cherqui D, Panis Y, Rotman N, Fagniez PL: Emergency liver resection for spontaneous rupture of hepatocellular carcinoma complicating cirrhosis. Br J Surg 1993;80:747-749.
9 Leung KL, Lau WY, Lai PBS, Yiu RYC, Meng WCS, Leow CK: Spontaneous rupture of hepatocellular carcinoma. Conservative management and selective intervention. Arch Surg 1999;134:1103-1107.

10 Flowers BF, McBurney RP, Vera SR: Ruptured hepatic adenoma. A spectrum of presentation and treatment. Am Surg 1990;56:380-383.

11 Iwatsuki S, Todo S, Starzl TE: Excisional therapy for benign hepatic lesions. Surg Gynecol Obstet 1990;171:240-246.

12 Terkivatan T, De Wilt JHW, De Man RA, Van Rijn RR, Tilanus HW, Ijzermans JNM: Treatment of ruptured hepatocellular adenoma. Br J Surg 2001;88:207-209. 